\title{
Challenges in learning Anatomy by first MBBS students of 2016-17 batch its difficulties and assessment methods preferred by them - a feedback study
}

\author{
Sudakshina Chakrabarti ${ }^{1, *}$, Gunapriya Raghunath ${ }^{2}$, Vijayalakshmi ${ }^{3}$ \\ ${ }^{1}$ Assistant Professor, ${ }^{2}$ Professor and Head, ${ }^{3}$ Professor, Dept. of Anatomy, Saveetha Medical College, Chennai, Tamil Nadu, India
}

*Corresponding Author:

Email: sudhianat@gmail.com

Received: $27^{\text {th }}$ February, 2018

Accepted: $28^{\text {th }}$ March, 2018

\begin{abstract}
Introduction: The first year MBBS students as they walk into the medical colleges face multiple challenges in the first few months of their course. The subject of medical Anatomy and its subdivisions forms a vast portion of their overall curriculum in first year MBBS with maximum teaching hours. Students face disinterest, lack of understanding, inability to recall and are many a times unable to cope up with the demand of this subject. This study was undertaken to address the problems of students of $1 \mathrm{st}$ MBBS in learning Anatomy, methods to rectify these problems and assessment methods and interval as preferred by students.

Objectives: 1. To detect the problems faced by students of 1st MBBS in learning Anatomy and view of students to proposed methods of rectification; 2. To analyze the students view regarding assessment methods and interval in Anatomy.

Materials and Methods: Study was conducted on 150 MBBS students on completion of 1st MBBS exams by means of structured questionnaire distributed to them. Students were exposed to regular teaching methods in department of Anatomy and feedback of students regarding problems faced in learning Anatomy and their views regarding proposed rectification methods were obtained. The feedback of students on assessment methods and interval was also obtained. The results were analyzed.

Results: Students faced problems in learning histology and this was because they were unable to identify slides. They also faced problems in understanding embryology. The assessment methods preferred by them was written test for theory in form of short answer questions [43\%] and monthly assessment [55\%] To rectify their problems, they felt more active learning methods like quiz, students seminars, and more frequent revisions to be integrated in the curriculum of Anatomy. Statistical analysis of both questionnaire was done using SSPS software and p value was $<0.001$.

Conclusion: This study thus evaluates the student's opinion regarding Anatomy and its subdivisions. Thus, it calls for a better planning of the curriculum, assessment techniques, revision schedule, etc. to bring about a more effective and apprehensive teaching and learning of Anatomy. This study thus concludes that an integration of newer technologies with traditional methods of teaching Anatomy and active teaching would be beneficial for the students.
\end{abstract}

Keywords: Feedback, Problems, Assesment, Students, Anatomy.

\section{Introduction}

The first MBBS students as they walk into the medical colleges are exposed to a totally new environment of teaching and learning as it is a professional course. The subject of medical Anatomy which forms a major part of the first year curriculum has to be dealt with at this point of time when the students has to adjust to a completely new surrounding just out from school. At this point of time it calls for addressing certain important values and mannerisms in the students and confidentiality in dealing with cadavers. ${ }^{1}$ It is not only the sole responsibility of Anatomist to impart skill and knowledge to the students but also calls for the development of right attitude in dealing with their problems in a professional way. ${ }^{2}$ The role of skilled Anatomy demonstrator has to stand the challenges of the ever changing medical curriculum to make the students not only compatible to face the clinics but also to develop right mannerisms in them. ${ }^{3}$

The teaching methodologies which are implied on the first year students are normally framed out by the university heads, senior faculty members according to MCI and UGC guidelines. There is a need in this hour that we take into consideration, the views and regular feedbacks of the students during and after completing their first year examinations for betterment in teaching practices in the first year subjects. The student's view cannot be totally overlooked and this can be extremely useful for us to bring about innovations in teaching and learning methodologies of clinical Anatomy. ${ }^{4}$

Anatomy as a subject in first MBBS has vast portions and many subdivisions which needs the student to know in detail about Gross Anatomy, Histology, Osteology, and Embryology to certain extent surface and Radiological Anatomy also. Among these in Saveetha University, Gross Anatomy and Histology deserve special mention. There are innumerable problems which are faced by the new comers in these subdivisions of Anatomy as they walk into the medical college.

There is no doubt that demonstration and discussion of cadaveric specimens forms the backbone of teaching and learning of Gross Anatomy. ${ }^{5}$ But in recent times there is a scarcity of cadavers and also reduction of course duration of Anatomy in first MBBS which makes way for newer and innovative teaching methodologies in Anatomy. Thus, this study was undertaken to evaluate the problems faced by first 
MBBS students in the important subdivisions of Anatomy and the students view towards certain proposed methods of solving their problems. Most of the 1st MBBS on obtaining oral feedback feel didactic lectures in Anatomy are boring and they feel its very difficult to concentrate and understand the topics taught. ${ }^{6}$ There is a continuous debate on exposing medical students to cadavers and whether teaching anatomy without use of cadavers can be effectively done. The use of other modalities of teaching gross anatomy by judicious use of audiovisual aids, dissection videos to replace exposure to cadavers for students is a topic of debate and most of studies do prefer cadaveric dissection in first year of MBBS. ${ }^{7}$

\section{Aim and Objectives}

1. To detect the problems faced by first MBBS students invarious subdivisions of Anatomy with the help of questionnaire.

2. Analysis of the student's feedback regarding assessment methods and interval.

3. Critically evaluate the student's view regarding rectification methods for the problems in learning Anatomy.

\section{Materials and Methods}

150 MBBS students of 2016-17 batch in Saveetha Medical College and Hospital were exposed to regular teaching pattern in Anatomy i.e. didactic lecture classes for theory, demonstration of specimens, bones in dissection hall and demonstration of slides in histology laboratory. Lecture classes were conducted primarily in Gross Anatomy, Embryology and Histology, in large group with power point presentation. In dissection hall, groups of 18 students were allocated in each table and demonstration of specimens were carried out. 2 quiz programs and 3 programs of student's seminar was conducted during the academic year. Assessment was done as 3 internal examinations conducted for theory and practical at the end of regions over a period of 10 months along with this unit tests were carried out monthly for theory and practical. The study was conducted by providing structured questionnaire to 150 students irrespective of their performances in Anatomy throughout the year 2 sets of validated questionnaire were provided to the students, the first set had 7 multiple choice questions, the second set of questions were of closed end type, requiring either positive or negative response. To determine the content validity the framed questions were discussed with 5 experts from the same specialty and the content validity index was close to $100 \%$. The face validity was determined by non-experts. The construct validity was tested using statistical analysis of questions answered and the CRONBACH's ALPHA was 0.72, which indicated the scale was reliable.

This study was conducted on the students after they completed their first MBBS examination. To prevent any bias, all students were instructed not to write their names on the questionnaire.

In the first questionnaire, they were asked all close ended questions in which they just had to read carefully and choose the correct option.

The following questions were asked in the first questionnaire

1. Divisions of anatomy which you faced most difficulties. Choose any one

a. Gross Anatomy

b. Histology

c. Embryology

d. All of the above

2. Problems faced in Gross Anatomy by you. Choose any one

a. Disinterest

b. Inability to identify specimen

c. Inability to correlate theory with specimens

d. Inability to recall

3. Problems faced in histology by you. Choose any one

a. Disinterest

b. Inability to identify slides

c. Inability to comprehend

4. Problems faced in embryology. Choose any one which is the most common problem.

a. Disinterest

b. Inability to follow the sequence of events

c. Inability to correlate theory knowledge in identifying charts and models.

5. Evaluation method for theory, which you feel is most appropriate. Choose one.

a. Structured descriptive question

b. Short answer questions

c. MCQs

d. Combination of the above

6. Evaluation method for practical which you feel is most appropriate. Choose one.

a. Spotters and discussion of specimens

b. Spotters and discussion of histology

c. Both of the above

7. Interval of assessment Choose any one

a. Weekly

b. Biweekly

c. Monthly

d. At the end of the region.

15 minutes time was given for them to complete the questionnaire. They were given $2^{\text {nd }}$ set of questionnaires where certain proposed methods of rectification were framed and students were asked to answer YES / NO for the methods, which they feel will improve their performance and can be a probable solution. The questions in this set were all closed end type and were framed after discussing with 5 faculty members thus attempting to develop an appropriate scale.

The following questions were asked. 
1. Introducing quizzes, student seminars, tutorials and written test at end of each region would help you to improve.

2. Inculcating habits of self and group reading in dissection hall with already demonstrated specimens and bones would help you to improve.

3. Embryology to be taught in sequence coordinating with gross Anatomy would help you to improve.

4. Liberal use of audio visual aids such as dissection videos and animation would help you to improve.

5. More frequent revisions would help you to improve.

6. Reducing the speed of teaching and repeating key points would help you to improve.

Students were given adequate time to answer appropriately and they were encouraged to answer all the questions and they were instructed not to write their names on the questionnaires. The questionnaire was collected back from the students and the results were statistically analyzed and represented.

\section{Observation and Results}

In the first questionnaire, in question No 1, the students were asked to choose the subdivision of Anatomy in which they had difficulties in learning. The majority of students chose histology [40\%] which showed the students were not able to cope up and understand histology easily this is shown in Table 1

In the following question, certain specific problems with regards to gross Anatomy was asked in which the point regarding inability to correlate theory with specimens got maximum importance as a most common problem $63 \%$ Table 1 Students also felt inability to identify specimens is a major problem in Gross Anatomy. Histology formed the major brunt of problems for 2016-17 batch and most common difficulty in histology over the entire course was inability to identify slides which was $76 \%$ and it showed that more attention is required in teaching and demonstrating histology. Table 1 In Embryology students felt they were unable to follow the sequence of events [72\%] and they are not able to apply the theory knowledge with the charts and models shown to them as shown in Table 1.

On analysis of methods and interval of assessment, students preferred monthly assessments [55\%] and assessment at the end of each region [25\%]. Regarding method of assessment in theory, most of students preferred short answer questions [43\%] a combination of structured descriptive questions, short answer questions and MCQs was 20\%. Regarding practical assessment students preferred both spotters and discussion in gross anatomy and histology at regular intervals as shown in Table 1

In the second questionnaire students were asked to answer YES/ NO certain proposed methods of teaching and learning Anatomy for improving their standards and thus to help them to solve their problems. As shown in Fig. 1, it is evident that students preferred quizzes, subject seminars and written test at end of each region above all other rectifying methods [68\%]. They also wanted time and motivation for self and group reading of already demonstrated bones and specimens in dissection hall. [73\%]. Students preferred self reading and discussion of already demonstrated specimens and bones in dissection hall with their batch mates as group discussions [Fig. 2]. They preferred embryology to be taught in coordination with gross Anatomy to correlate the development with structure [Fig. 3]. Liberal use of audiovisual aids and animation was also recommended by students as $58 \%$ preferred it. [Fig. 4] Since they were unable to recall the slides in histology and spotters in gross anatomy they too wanted more revisions and repetition of key points multiple times by facilitators. [Fig. 5] Reducing the speed of teaching and repetition will help to improve the students was the preferred opinion. [Fig. 6]

Statistical analysis done using parametric tests by SPSS software showed $\mathrm{p}$ value as $<.001$ for all the questions in $1^{\text {st }}$ set of questionnaire. When the second set of questionnaire were subjected to parametric statistical test it also showed the $\mathrm{p}$ value to be $<0.001$. As the study involves limited subjects it calls for further studies in future with larger sample size.

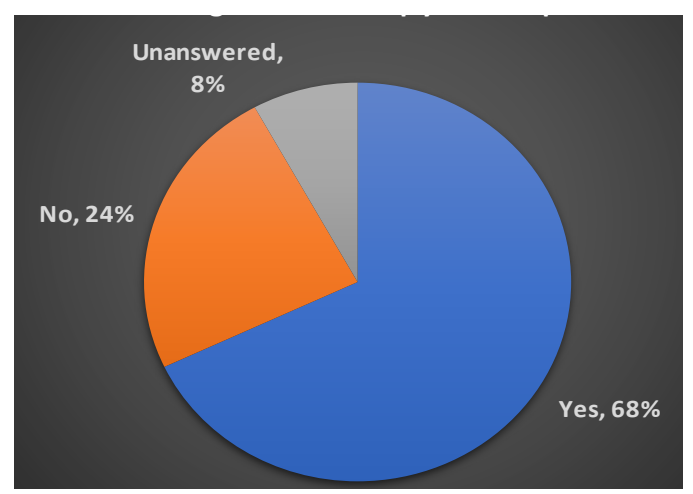

Fig. 1: Introducing quizzes, student seminars, tutorials and written test at end of each region would help you to improve

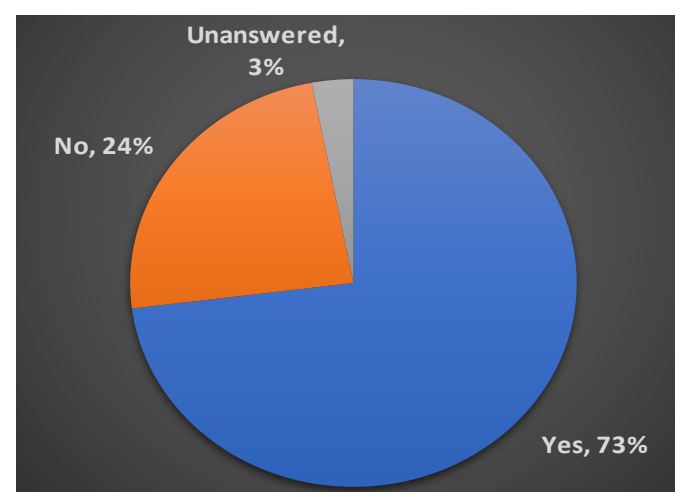

Fig. 2: Inculcating habits of self reading in dissection hall with already demonstrated specimens and bones 


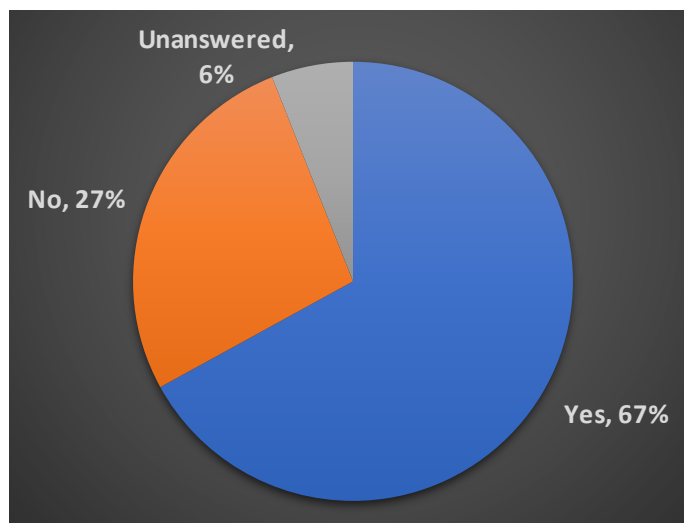

Fig. 3: Embryology to be taught in sequence coordinating with gross Anatomy would help you to improve

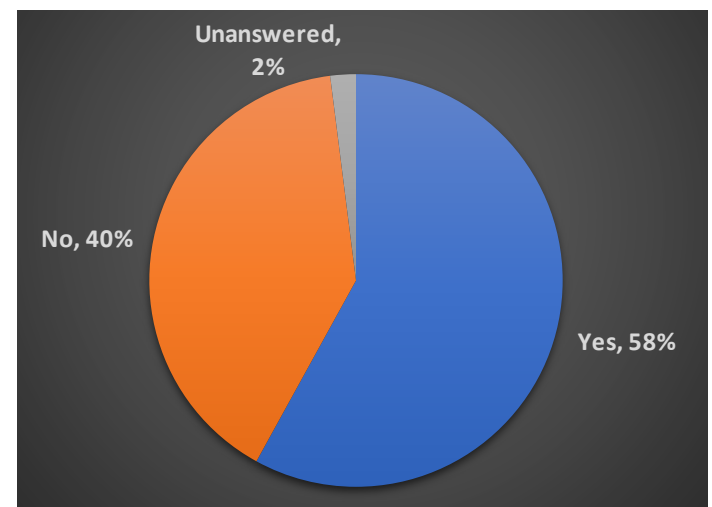

Fig. 4: Liberal use of audio visual aid and animation

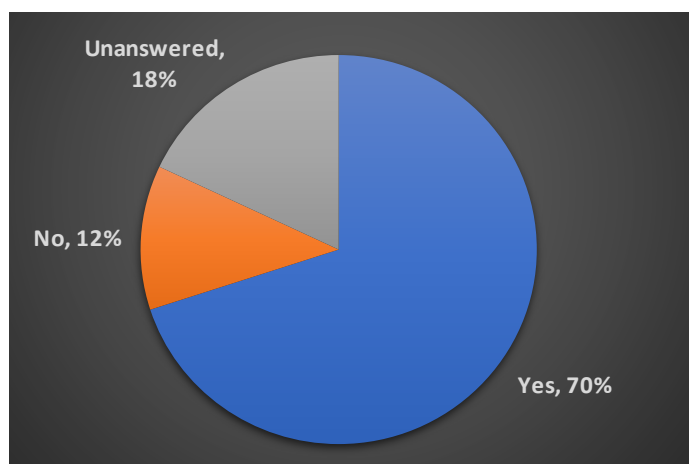

Fig. 5: Frequent revisions

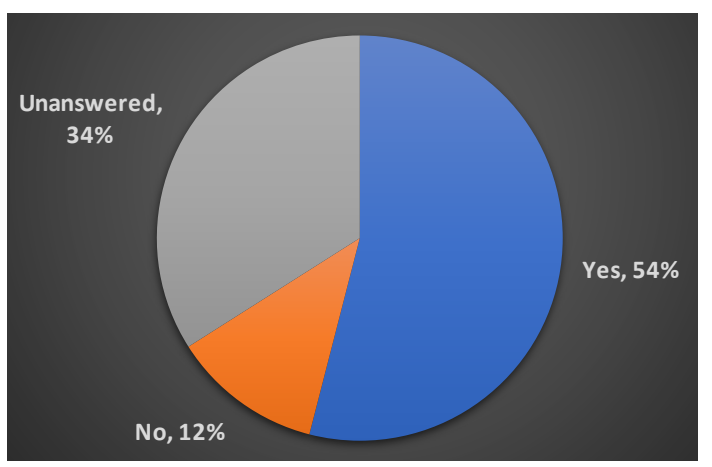

Fig. 6: Speed of teaching reduction and repeatition of key points

Table 1: Showing responses to $1^{\text {st }}$ questionnaire

\begin{tabular}{|l|l|c|}
\hline \multicolumn{1}{|c|}{ Questions } & \multicolumn{1}{|c|}{ Subdivisions } & $\begin{array}{c}\text { Percentage of } \\
\text { positive response }\end{array}$ \\
\hline $\begin{array}{l}\text { 1. Divisions of anatomy which } \\
\text { you faced most difficulties. }\end{array}$ & a. Gross Anatomy- & $25 \%$ \\
Choose any one & b. Histology- & $40 \%$ \\
& c. Embryology- & $30 \%$ \\
& d. All of the above- & $5 \%$ \\
\hline $\begin{array}{l}\text { 2. Problems faced in Gross } \\
\text { Anatomy by you. Choose any one }\end{array}$ & a. Disinterest- & $5 \%$ \\
& b. Inability to identify specimen - \\
& c. Inability to correlate theory with & $20 \%$ \\
& specimens & $63 \%$ \\
\hline 3. Problems faced in histology by & d. Inability to recall - & $12 \%$ \\
you. Choose any one & a. Disinterest - & $4 \%$ \\
& b. Inability to identify slides - & $76 \%$ \\
\hline 4. Problems faced in embryology & c. Inability to comprehend - & $20 \%$ \\
Choose any one the most & a. Disinterest - & $5 \%$ \\
common problem & b. Inability to follow the sequence of events & $72 \%$ \\
& c. Inability to correlate theory knowledge in & $23 \%$ \\
\hline 5. Evaluation method for theory & identifying charts and models - & \\
which you feel is most & a. Structured descriptive question - & $22 \%$ \\
appropriate (choose one) & b. Short answer questions - & $43 \%$ \\
& c. MCQs - & $15 \%$ \\
\hline 6. Evaluation method for & d. Combination of the above - & $20 \%$ \\
\hline
\end{tabular}




\begin{tabular}{|l|l|c|}
\hline practicals which you feel is most & b. Spotters and discussion of histology- & $7 \%$ \\
appropriate (choose one) & c. both of the above- & $88 \%$ \\
\hline 7. Interval of assessment Choose & a. Weekly & $7 \%$ \\
any one & b. Biweekly & $13 \%$ \\
& c. Monthly & $55 \%$ \\
& d. at the end of the region. & $25 \%$ \\
\hline
\end{tabular}

\section{Discussion}

Medical education is undergoing extensive and revolutionary changes in present times. With the advent of innovative teaching methodologies, with the use of internet, electronic media, educative videos, conferences, CMEs the traditional methods of teaching Anatomy are facing challenges. It is the need of the hour to address the true needs of the students, assess their problems in learning Anatomy and provide suggestions to solve the problems. The view of the students regarding their disinterest and reluctance to read a particular subdivision of Anatomy has been addressed in this study. The reason for the disinterest has been too emphasized. This study was conducted, keeping all the traditional methods of teaching in practice i.e. cadaveric teaching for practical, didactic lectures in theory for gross, embryology, histology, discussion and demonstration of histology slides. According to the study by S K Nagar, the best method of learning in the dissection hall is teaching and learning by cadaveric dissection and demonstration. ${ }^{8}$ Even in the study by Chapman SJ cadaveric dissection is a favorable approach for achieving important learning objectives in the field ofanatomy. ${ }^{9}$ In the present study too, [Fig. 5] students preferred to have multiple revision of already demonstrated cadaveric specimen and bones in dissection hall to improve their confidence and skill.

In the study by Shoaib Rafique students preferred multiple choice questions as best method of assessment. ${ }^{10}$ Whereas in the study conducted by Rashmi Jaishwal, 55.03\% of students favoured descriptive and short essay questions with multiple choice questions as a pattern of examination and only $21.7 \%$ students agreed for multiple choice questions with true/false type questions. ${ }^{4}$ In the present study students preferred a combination of descriptive questions, short answers and MCQs as method of assessment in theory. [Table 1] In our institution a combination of descriptive structured questions, short answer questions and very short answer questions are presently used for assessment of theory and we are considering of including MCQ $\mathrm{s}$ in the future especially after the students preference. Considering the interval of assessment about $70 \%$ of students preferred weekly test in the study conducted by S K Nagar ${ }^{8}$ whereas in study conducted by Rashmi Jaishwal ${ }^{4}$ students preferred test at the completion of region or part which is very similar to the present study. The assessment methods which is currently followed is written tests at end of each region which was preferred by the students [25\%] and in present study most of students preferred monthly tests [Table 1] which can be implemented from next academic year.

According to B Karmer solutions to problems in learning Anatomy can be addressed by providing more time, scheduling and restructuring lectures, using more visual aids, and including tables and summaries which can be easily recalled. ${ }^{11}$ It is important to emphasize that students will only remember $20 \%$ of what they read, $30 \%$ of what they hear, $40 \%$ of what they see, $50 \%$ of what they say, and $60 \%$ of what they do. This average increases to $90 \%$ for information they say, hear, see, and do. ${ }^{12}$ Other studies have shown that students learn better by using active learning strategies, because active learning methodologies reach all types of students. ${ }^{13-15}$ Active learning methods promote thinking through reasoning and improve problem solving and decision making skills. In the present study, students preferred active learning methods in form of quizzes, students' seminars and they too preferred self and group studies in already demonstrated specimens in dissection hall. [Fig. 2] Students in present study preferred a reduction in speed of teaching and emphasis on key points at end of lectures. Students strongly felt that more frequent revisions would help them to remember theory and practical aspect of the subject. In the study by Esther M Bergman students felt that repetitive studying of the subject increases retention of knowledge to a greater extent than stricter assessment, and teaching in context enhances motivation. ${ }^{16}$ As this study is doubly blind, the responses and performance of students were not correlated and students were asked not to reveal their names in the questionnaires to maintain confidentiality. The responses of students are overall view of the teaching methodologies already practised or intended to be practised in department of Anatomy and thus performance based bias was avoided in this study. This can be considered as a drawback as the responses were not analyzed based on the performance of the students.

\section{Conclusion}

Based on feedback procured the present study shows a need for modification in curriculum, assessment method, time frame, rescheduling of portions and introduction of more interactive teaching and learning methodologies in Anatomy. Students were seen in this study to prefer traditional method of teaching with modification. Students also preferred active involvement of teaching faculty in revision classes and more frequent revisions. Importance to key 
points, more frequent revisions by teachers, self and group study of demonstrated specimens and slides were given more importance than to computer aided teaching methods in form of audiovisual aids, animation. On the other hand, students preferred active teaching and learning strategies in form of quizzes, students' seminars and written test at end of each region. This calls for more active participation from the Department of Anatomy to conduct more of these programs. This study thus shows there is a constant need for modification of curriculum, planning and scheduling of lectures, assessment techniques, incorporation of innovative active teaching and learning methodologies and receiving more frequent feedback from students to bring about the above changes. In this study students' responses were not analyzed according to their performance thus attempting at a bias free feedback from them. This study attempts to conclude that students prefer traditional methods of teaching with modifications and active learning should be incorporated into teaching.

\section{References}

1. Graham HJ. Patient confidentiality: implications for teaching in undergraduate medical education. Clin Anat. 2006;19(5):448-55.

2. Pangaro LN. A shared professional framework for anatomy and clinical clerkships. Clin Anat. 2006;19(5):419-28.

3. Lockwood AM, Roberts AM. The anatomy demonstrator of the future: an examination of the role of the medicallyqualified anatomy demonstrator in the context of tomorrow's doctors and modernizing medical careers. Clin Anat. 2007;20(4):455-9.

4. Rashmi Jaiswal *, Sameer Sathe, Vivekanand Gajbhiye, Rashmi Sathe. Students Perception on Methods of Anatomy Teaching And Assessment, International Journal of Anatomy and Research, Int J Anat Res. 2015, 3(2):1103-08.

5. Aziz MA, Mckenzie JC, Wilson JS, Cowie RJ, Ayeni SA, Dunn BK. The human cadaver in the age of biomedical informatics. Anat Rec. 2002(1);269:20-32.

6. Sudakshina Chakrabarti, Shilpakala, Gunapriya Raghunath, P K Sankaran. Teaching and learning perception of Anatomy by first MBBS 2014-15 batch students. Indian Journal of Clinical Anatomy and Physiology. 2017;4(1):87-91.
7. McLaghlan JC, Bligh J, Bradley P, Searle J. Teaching anatomy without cadavers. Med Educ. 2004;38(4):418424.

8. S K Nagar, Ojaswini Malukar, Dharti Kubavat, Vipul Prajapati, Dimple Ganatra, Ajay Rathwa. Students' perception on anatomy teaching methodologies. National journal of medical research. 2012:2(1):111-112.

9. Chapman SJ, Hakeem AR, Marangoni G, Prasad KR. Anatomy in medical education: perceptions of undergraduate medical students. Ann Anat. 2013Oct;195(5):409-14.

10. Shoaib Rafique, Hasan Rafique, Students' feedback on teaching and assessment. J Pak Med Assoc. 2013 Sep;63(9):1205-9.

11. B Karmer and J T Soley. Medical student perception on problems in Anatomy. East African medical journal. August 2002;79(8):408-414.

12. Bonwell CC, Eison JA. Active Learning: Creating Excitement in the Classroom. Washington, DC: George Washington University. 1991.

13. Lujan HL, Dicarlo SE. First year medical student prefers multiple learning habit. Adv Physios Educ. 2006 Mar;30(1):13-6.

14. Langlois J, Thach $\mathrm{S}$. Teaching and learning styles in the clinical setting. Family Medicine. 2001;33(5):344-6.

15. Lujan LH, Dicarlo SE. Too much teaching, not enough learning: what is the solution? Advance in Physiological Education. Adv Physiol Educ. 2006 Mar;30(1):17-22.

16. Esther M Bergman, Anique BH de Bruin, Andreas Herrler, Inge WH Verheijen, Albert JJA Scherpbierand Cees PM van der Vleuten. Students' perceptions of anatomy across the undergraduate problem-based learning medical curriculum: a phenomenographical study. BMC Medical Education. 2013 13:152. https://doi.org/10.1186/14726920-13-15.

How to cite this article: Chakrabarti S, Raghunath G, Vijayalakshmi. Challenges in learning Anatomy by first MBBS students of 2016-17 batch its difficulties and assessment methods preferred by them - a feedback study. Ind J Clin Anat Physiol. 2018;5(3):416-421. 